DOI 10.37882/2223-2982.2020.12.29

\title{
ОБ «ОБЩЕМ ПАДЕЖЕ» СОВРЕМЕННОГО НЕМЕЦКОГО ЯЗЫКА
}

\section{ABOUT THE "GENERAL CASE" OF MODERN GERMAN}

\section{Panfilova \\ L. Bubekova}

Summary: In the article, the author examines the psycholinguistic and linguistic problems of using the case system of the modern German language. Cases today are the main carriers of morphological meanings, which in turn form a number of oppositions of a paradigmatic nature. Also, cases act as regulators of syntactic relations, which demonstrate the relationship of the noun and other members of the sentence. The work examines the category of case, its functional features and characteristics, and also interprets the nominative case in the system of the modern German language. As a result of the research carried out on the basis of the analyzed factors, the author comes to the conclusion that a reasonable solution is to single out the general case as a category with zero marking.

Keywords: German, general case, language system, usus

\author{
Панфилова Валентина Михайловна \\ К.n.н., дочент, Казанский федеральный университет \\ valova55v@yandex.ru \\ Бубекова Лариса Борисовна \\ К.филол.н., дочент, Елабужский институт (филиал) \\ Казанского федерального университета \\ bular@yandex.ru
}

Аннотация: В статье автором рассматриваются психолингвистические и лингвистические проблемы использования падежной системы современного немецкого языка. Падежи сегодня являются основными носителями морфологических значений, который в свою очередь образуют ряд оппозиций парадигматического характера. Также падежи выступают в качестве регуляторов синтаксических отношений, которые демонстрируют связи существительного и других членов предложения. В работе рассматривается категория падежа, ее функциональных особенностей и характеристик, а также трактуется именительный падеж в системе современного немецкого языка. В результате выполненного исследования на основании проанализированных факторов, автор приходит к выводу, что целесообразным решением является выделение общего падежа как категории с нулевой маркированностью.

Ключевые слова: немецкий язык, общий падеж, языковая система, узус.

правил и понятий, а в области строевых специфичных признаков немецкого языка, обусловленных комплексом внешних и внутренних факторов. В сознании носителей современного немецкого языка совокупность данных факторов фиксируется как тенденция, ориентированная на упрощение используемой флективной морфологии имен существительных в рамках субстантивных групп.

Если рассматривать категорию общего падежа в немецком языке, необходимо выполнять это в совокупности и в тесной взаимосвязи с артиклеобразными словами, а также с артиклем. Это обусловлено тем, что данные элементы языковой системы чаще всего выполняют роль носителей морфологических падежных показателей имени существительного в процессе его употребления.

Нельзя забывать, что выражение падежных форм сообщается с родовыми свойствами имен существительных, что имеет особое значение для различия и разграничения отношения между субъектами и объектами, выстраивающихся в ходе высказываний при эксплуатации имен существительных в женском или среднем роде в общем или винительном падеже. Это объясняется тем, что в данном случае они не несут отличительных специфичных грамматических признаков. Ярким примером является следующее предложение: «Das Kind küsst die Mutter», в котором наблюдается омонимия выразительных падежных средств для используемых имен существительных. Устранить омонимию удается только посредством применения правила порядка слов, на 
первом месте всегда находится субъект предложения.

Если говорить о грамматической выразительности немецкого языка, она достигается посредством использования различных средств: прилагательных, местоимений, порядка слов существительных, артиклеобразных слов. Рассмотрим два примера:

1. In der Krise der liberalen Demokratie wird die Krise des autoritären Charakters sichtbar. В данном случае мы наблюдаем прикрытую позицию существительных, которая дает возможность идентификации падежа на основании грамматических показателей.

2. Jetzt steht nicht mehr Dekonstruieren auf der Hitliste, sondern Konstruktivität. Здесь мы уже имеем неприкрытую позицию, которая отличается отсутствием падежных признаков.

При этом имя существительное и имена собственные не имеют выраженных четких грамматических маркеров, что является нарушением употребления слов. Это нарушает структуре немецкого языка, где сохраняются флективные элементы даже в условиях увеличения аналитических тенденций. Процессы данного типа имеют историческое происхождение, однако сегодня они выражаются в широком распространении и применении падежно амбивалентных словарных форм имен существительных [4].

Среди всех имен существительных в немецком языке избыточность с позиции маркирования отличаются формы, образующиеся в сложной комбинации показателе трех типов: рода, падежа и числа, что обуславливает языковую нагрузку [5]. Имена существительные требуют грамматического выражения синтаксических отношений посредством многообразия маркеров падежей, которые демонстрируют принадлежность к тому или иному виду склонения, опираясь на совокупность признаков формального гибкого характера.

Сегодня для немецкой языковой системы свойственно увеличения класса позиций, в которых имя существительное не имеет грамматически оформленных признаков. Таким образом, существительные все чаще применяются в позиции неприкрытого типа. Это отчетливо прослеживается в следующих примерах:

1. zu Gehör bringen;

2. eine Art Mensch;

3. Obacht geben;

4. seine Stellung als Lehrer;

5. in Form.

Рассмотрение приведенных и других примеров дает основание выделить «общий падеж» в качестве специфичной неопределенной формы имени существительного, которая разрывает взаимосвязь с устоявшейся па- радигмой [6]. Следующей обнаружившейся тенденцией является превалирование устойчивых словосочетаний в пуле образований с «общим падежом»:

1. mit Hilfe von;

2. zu Hause;

3. nach Hause и так далее.

Ряд исследователей склоняются к мнению о необходимости признания нескольких разновидностей общего падежа в современном немецком языке:

1. Падеж, который позволяет использовать формы как именительного, так и родительного падежей.

2. Падеж, который позволяет применять формы дательного и именительного падежей.

3. Падеж, который позволяет использовать формы родительного и еще одного падежа и так далее [7, 8, 9].

Альтернативным вариантом является применение общего падежа как одного из вариантов именительного падежа с тенденцией проникновения в другие позиции, что обусловлено монофлексией. Если обратиться к исторической составляющей, трактование общего падежа как импульса к монофлексии является оправданным. Однако в условиях сегодняшнего немецкого языка очевидна необходимость дифференцированного подхода, который комплексно учитывал бы совокупность факторов, влияющих на расширение сферы использования и присутствия общего падежа как в рамках устной, так и в рамках письменной речи.

Сегодня проблема общего падежа неразрывно связана с тенденцией к употреблению имен существительных без артиклей. Такое применение представлено посредством совокупности явлений системного и асистемного характера. При этом каждое явление из совокупности располагается в области широкого варьирования форм языка, инструментов выражения отношений между падежными свойствами.

Если говорить о случаях отсутствия артикля, которые были упомянуты ранее, они относятся к предметам нормативных грамматик. Данная область относится к морфосинтаксису и демонстрирует наиболее выраженные языковые факты, которые можно объединить в категории на основании сходства ситуаций и условий, ведущих к элиминированию артикля. При этом выделяют две зоны:

1. Зона немотивированного артиклевого варьирования.

2. Зона безартиклевого употребления имен существительных.

Данные зоны проявляются в аналитических словосочетаниях глагольно-именного типа, где артикль присутствует (например, eine Umfrage halten) или отсутствует (Einzug halten). Здесь важно отметить, что все 
чаще в языковой системе применяются безартиклевые употребления (не только в разговорной речи и рекламных средствах, но также в нормативных институциональных наименования: Vorsicht Volk!, Satirepartei auf Abwegen, GLS Bank и так далее). Параллельно с этим происходит активными темпами процесс создания новых предпосылок отказа от артикля при именах существительных.

\section{Основная часть}

Были рассмотрены группы явлений использования имен существительных без артиклей как выражение тенденций, обусловленных современной системой языка. Такое явление как безартиклевость проявляется в текстах и условиях различных жанров:

1. Безартиклевость является признаком предложных образований, которые относятся к сложносоставным предлогам, образующимся на базе сочетания предлога и имени существительного. Например, это можно наблюдать в следующих образованиях: aus Rücksicht, in Form, uf Dauer.

2. Безарктиклевость может быть обусловлена употреблением имен существительных в неприкрытой форме, то есть, когда с предлогами употребляются имена существительные неатрибутированного типа. В данных группах, как правило, отсутствует падежное маркирование, что принято связывать с влиянием, оказываемым разговорным стилем языка, что позволяет экономить усилия не только в ходе устной, но также и в ходе письменной речи. Примеры, в которых не выражены падежи: trotz Streick, außer Bewohner und Fahrzeuge. Второй пример похож с фразеологическими оборотами по типу von Mensch zu Mensch.

3. Безартиклевость обусловлена образованиями, которые включают имена существительные в функционал приложений, которые в современной языковой системе представлены различными типами и имею широкое распространение в круге современных дискурсов. Было выявлено, что явление безартиклевости постепенно расширяет диапазон влияния и употребления в результате группы языковых тенденций, указывающих на специфичный метод определения символов идентификации перед именами существительными, употребляемыми в функции приложений, которые при этом обозначают определенные сущ- ности при обобщающем именном значении [10]. В качестве примером можно рассмотреть следующие образования: eine Spur Machtlosigkeit, das Thema Rente, eine Art Theater.

Рассмотренное явление безартиклевости демонстрирует сильные колебания, говорящие об отсутствии устойчивости отношений в грамматике в рамках группы имен существительных. Тенденция к данному явлению сегодня отчетливо выражена и находит поддержку в совокупности сходных процессов, когда имена употребляются в нулевой форме.

Помимо этого, прослеживается усиление колебаний в процессе управления падежами относительно предлогов производного порядка. Данная тенденция демонстрирует широкую альтернативу значительного класса предлогов, приветствующих падежную вариативность $[11,12]$.

Таким образом, тенденция к применению существительных без артиклей является чертой современного немецкого языка, его разговорной и все чаще письменной речи. Зачастую она именуется как «укороченный немецкий». Однако важно отметить, что в письменном стандарте артиклю является нормой грамматического оформления и делает возможной реализацию широкого спектра коммуникативно-когнитивных задач.

\section{Зак^ючение}

Многочисленные случаи отказа от артикля при использовании имен существительных в рамках современной немецкой языковой системы нельзя относить к новациям. Они использовались и ранее, отражая последовательные динамические процессы сужения сферы воздействия флективной морфологии, сокращающей до минимума участие флективных маркеров для отображения грамматических отношений.

Расширение области использования безартиклевых форм является важным аргументов для выделения «общего падежа» в качестве нулевой формы. Важно отметить, что нулевая форма при этом является психолингвистической реальностью, так как она активным образом проявляет себя в различных средах использования современного немецкого языка, а ее существование осознается и признается носителями.

\section{ЛИТЕРАТУРА}

1. Уфимцева Н.В. Лингвистический и психолингвистический анализ структуры падежной системы (на материале русского языка): дис... канд. филол. наук. - М.: 1976.

2. Уфимцева Н.В. Языковое сознание: динамика и вариативность. - М., Калуга: Институт языкознания РАН (ИП Шилин И.В.), 2011. - 252 с. 
3. Шубина Э.Л. Словосочетания типа Nquant+ AdjN и eine Art+ AdjN в языке немецкой художественной литературы XX века: особенности грамматического оформления и лексического наполнения. - М.: Компания спутник, 2004. - 204 с.

4. Pavlov V. Die Deklination der Substantive im Deutschen. Synchronie und Diachronie. - Frankfurt a.Main: Peter Lang GmbH, 1995. - 252 P.

5. Braun P. Tendenzen in der deutschen Gegenwartssprache. Sprachvarietäten. 3. Aufl. - Stuttgart, Berlin, Köln, 1993. - 265 p.

6. Ревзин И.И. Структура немецкого языка. - М.: ОГИ, 2009. - 399 с.

7. Steriopolo 0. Intonation als Komplexphänomen // Germanistik in der Ukraine. - Jahresheft 4. - Kyjiw: Verlagszentrum der KNLU, 2009. - P. 75-86.

8. Duden. Elektronisches Universalwörterbuch: Richtiges und gutes Deutsch. - Dudenverlag, Bibliographisches Institut, F.A. Brockhaus AG, Langenscheidt KG, 2001

9. Щербакова А.В. 06 англо-американском влиянии на способ образования новых глаголов в современном немецком языке // Язык в мультикультурном мире: тезисы и материалы международной конференции [отв. ред. О.А. Кострова]. - Самара: СамГПУ, 1999. - С. 195- 196.

10. Бабенко Н.С. аналитические тенденции в современном немецком языке взгляд на некоторые грамматические процессы в группе существительного// Аналитизм в языках различных типов: сорок лет спустя. К 100 - летию со дня рождения В.Н. Ярцевой. Материалы чтений памяти В.Н. Ярцевой. Выпуск II. - М.: Эйдос, 2006. - С. 183-192.

11. Polenz P. v. Geschichte der deutschen Sprache. - 10., völlig neu bearb. Aufl. - Berlin, NY: Walter de Gruyter, 2009. - 240 P.

12. Черникова Н.В. Признаки языковой нормы. Язык образования и образование языка // Язык образования и образование языка. Великий Новгород: Изд-во НовГУ, 2000. - С 336-337

( П) Панфилова Валентина Михайловна (valova55v@уandex.ru), Бубекова Лариса Борисовна (bular@yandex.ru).

Журнал «Современная наука: актуальные проблемы теории и практики»

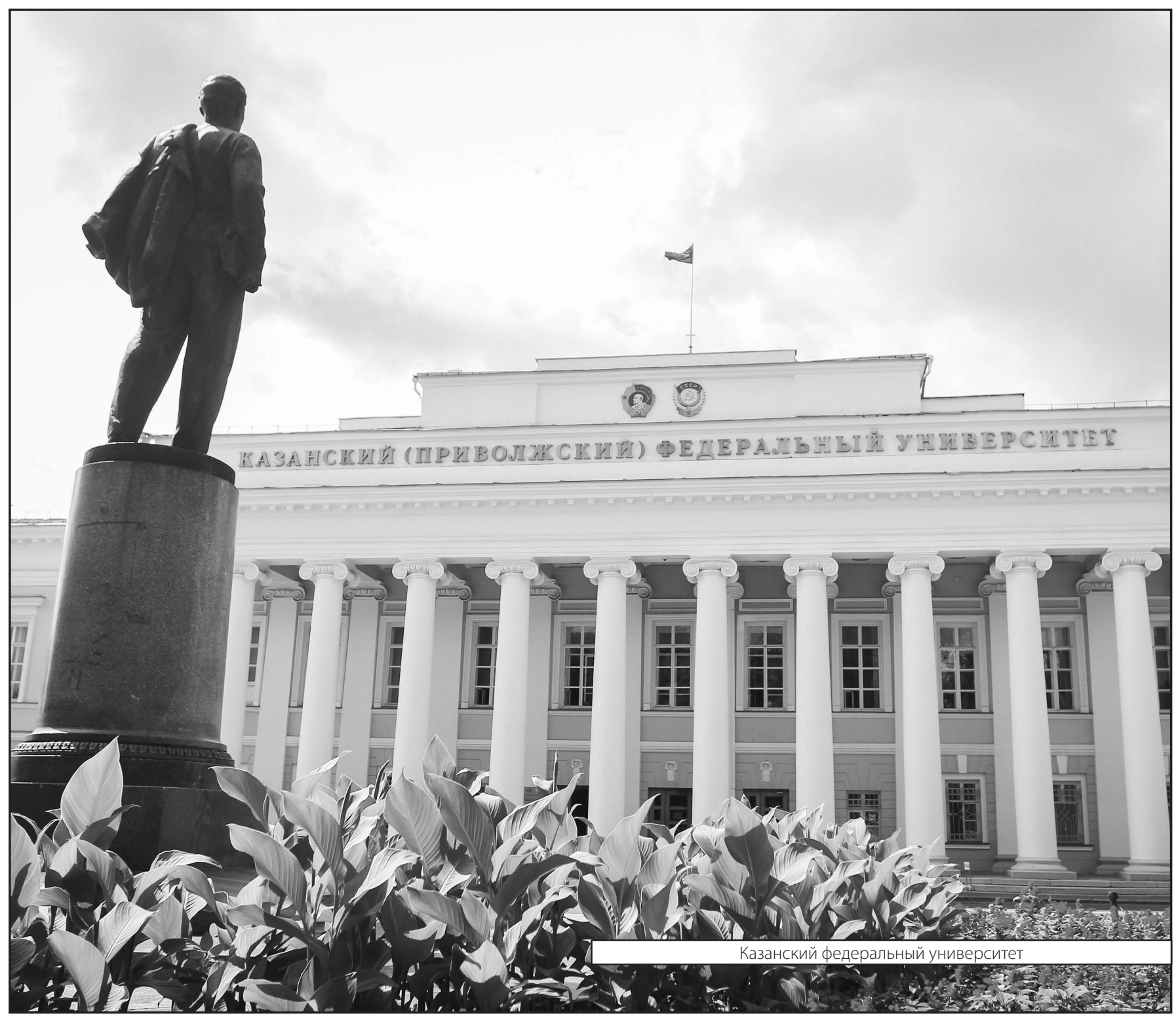

